\title{
Analysis of radio wave propagation in Lagos environs \\ ${ }^{1}$ Shoewu, $O$ and ${ }^{2}$ F.O. Edeko \\ ${ }^{1}$ Department of Electronic and Computer Engineering, Lagos State University, Epe Campus, Lagos, Nigeria \\ ${ }^{2}$ Department of Electrical/Electronic Engineering, University of Benin, Benin, Nigeria
}

\begin{abstract}
Various research studies have been carried out by different researchers on the behaviour of radio wave within different environment under different environmental and geographical conditions. The models derived are specific for the respective environment. To validate the model, field measurements were carried out at different locations within Epe town and its environs. The measurements system consist of live radio base stations transmitting at $900 \mathrm{MHz}$ and $1800 \mathrm{MHz}$. Downlink signal strength level data were collected using drive test exercise consisting of test mobile phones, TEMS investigating software, Maplnfo and Google earth. The respective path loss values were estimated and compared with existing model like OkumuraHata model for rural, suburban and urban areas. The result indicated an appreciable consistency with the empirical models except for rural areas.
\end{abstract}

Keywords: Pathloss, TEMS, Maplnfo, Google earth, GSM, Communication

\section{INTRODUCTION}

Signal quality and drop calls of mobile communication operators in buildings have being studied extensively for the last six years.

Knowledge of the phenomena involved in the path loss propagation in the vegetation is an important factor in the wireless telecommunication project. However, the electromagnetic modeling of the radio wave in this type of environment has been a challenge due to the great complexity of the environment aspects. The physical and geometric parameters of trees in nature are randomized. Hence, areas with vegetation are difficult to find models to represent them, characterizing the environment and attending the system specification, like frequency, transmitted power, and antenna heights.
These factors have motivated researchers to develop path loss propagation models capable to include essential characteristics of suburban and rural environments. The propagation medium is one of the most critical components of mobile communication system, requiring an appropriate modeling of its elements in order to accomplish studies to attend demands of different coverage areas.

This study is carried out at investigating the effectiveness of commonly used Okumura-Hata, COST -231, and free space models, which are used for macro cells within rural and suburban areas. This investigation of radio wave signals (GSM) is to cover Lekki city to Epe town. This investigation is limited to two different site within each of rural, suburban and urban area. The cities are Lekki and Victoria Island for urban, Epe town for suburban area and Ejirin and Imota villages as rural areas. 
Am. J. Sci. Ind. Res., 2011, 2(3): 438-455

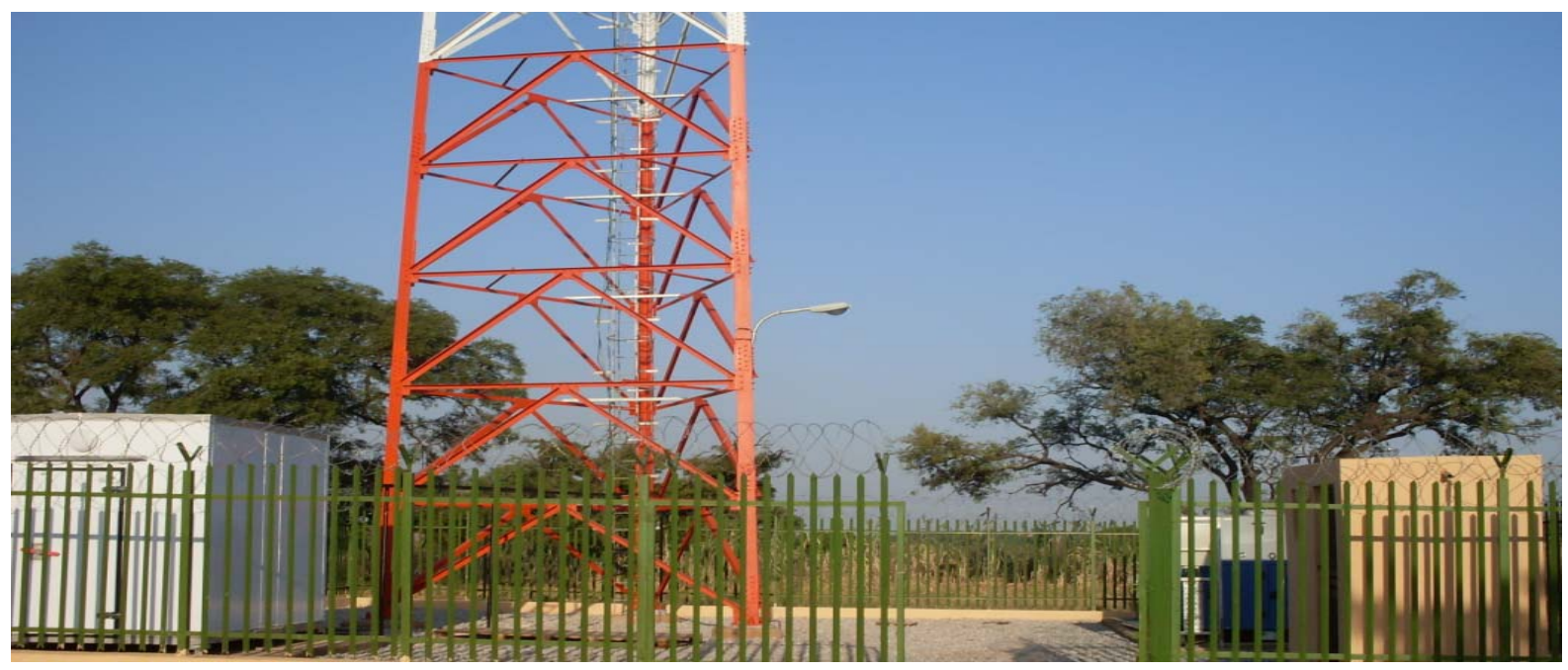

Fig 1.0: Radio signal Base Station along Lekki-Epe Road

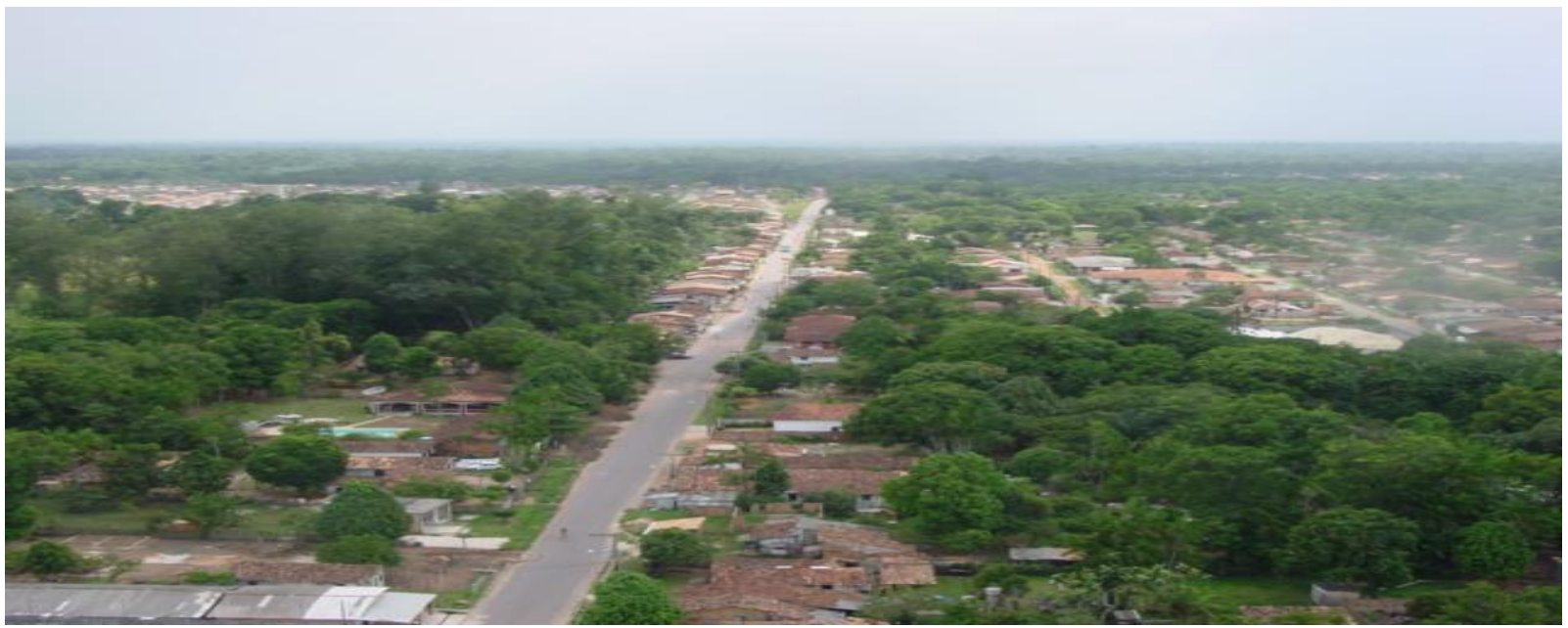

Fig 1.1: Arial View of Lekki-Epe road

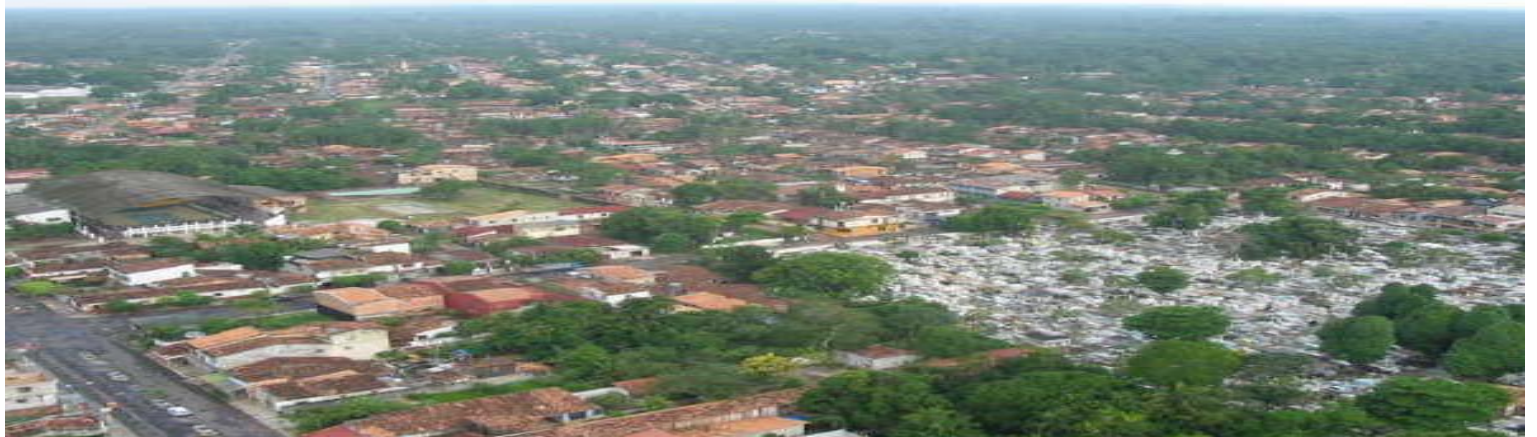

Fig 1.2: Arial View of Lekki-Peninsular (Urban) 
Application of study: In this study we investigated how effective the existing propagation models like Okumura-Hata model, COST-231 model, and Free Space model in Nigerian environment. If the path loss distribution as proposed by these existing models are in consonance with the measurement then, these models will be regarded as valid for use in cellular network planning for Nigerian rural, suburban, and urban areas.

The study is to investigate how effective are the existing propagation models like Okumura-Hata model model in Nigerian environment. If the path loss distribution as proposed by these existing models are in consonance with the measurement then, these models will be regarded as valid for use in cellular network planning for Nigerian rural, suburban, and urban areas.

\section{Characteristics of radio wave propagation models:}

As the path loss encountered along any radio link serves as the dominant factor for characterization of propagation for the link, radio propagation models typically focus on realization of the path loss with the auxiliary task of predicting the area of coverage for a transmitter or modeling the distribution of signals over different regions (Schmitz and Wenig, 2008).

Because each individual telecommunication link has to encounter different terrain, path, obstructions, atmospheric conditions and other phenomena, it is intractable to formulate the exact loss for all telecommunication systems in a single mathematical equation.

As a result, different models exist for different types of radio links under different conditions. The models rely on computing the median path loss for a link under a certain probability that the considered conditions will occur.

Radio propagation models are empirical in nature, which means, they are developed based on large collections of data collected for the specific scenario. For any model, the collection of data has to be sufficiently large to provide enough likeliness (or enough scope) to all kind of situations that can happen in that specific scenario. Like all empirical models, radio propagation models do not point out the exact behavior of a link, rather, they predict the most likely behavior the link may exhibit under the specified conditions.

\section{RADIO WAVES PROPAGATION MODELS}

\section{Free space model:}

The free space model assumes an ideal situation where there are no obstacles that could cause reflection, diffraction or scattering within the line-ofsight between the transmitter and receiving stations. Thus the attenuation of the radio wave signal is proportional to the distance from the transmitter. The receiver power density, at a distance $d$ from the transmitter, is expressed as:

$$
D=\frac{P_{t} A_{t}}{4 \pi d^{2}} \quad \text { wher }
$$

The receiver power density can also be written as

$$
D=\frac{P_{r}}{A}
$$

The Receive Power $\quad P_{r}=P_{t} A_{t} A_{r}(\lambda / 4 d)$

Path loss

$$
P_{L}=10 \log \left(P_{t} / P_{r}\right)
$$

$$
P_{L}=32.44+20 \log (f)+20 \log (d)
$$

Practically, the ideal situation upon which this model was derived is not realistic.

Radio wave signal power attenuation depends largely on the frequency band and terrain types between the transmitting and receiving antenna. The propagation path loss varies according to the terrain type and this should be given serious consideration in propagation path loss modeling. This is done using the correction factor for each terrain. A more realistic path loss model is the Okumura-Hata model for macrocells in rural and suburban areas.

\section{HATA MODEL FOR SUBURBAN AREAS}

The Hata Model for Suburban Areas, also known as the Okumura-Hata model for being a developed version of the Okumura Model, is the most widely used model in radio frequency propagation for predicting the behavior of cellular transmissions in city outskirts and other rural areas. This model incorporates the graphical information from Okumura model and develops it further to better suite the need. This model also has two more varieties for transmission in Urban Areas and Open Areas.(Emagbetere and Edeko, 2009)

Hata Model predicts the total path loss along a link of terrestrial microwave or other type of cellular communications. And is a function of transmission frequency and the average path loss in urban areas. 
Applicable to/under conditions: This particular version of Hata model is applicable to the transmissions just out of the cities and on rural areas where man-made structures are there but not so high and dense as in the cities (Shoewu and Adedipe, 2010). To be more precise, this model is suitable where buildings exist, but the mobile station does not have a significant variation of its height. This model is suited for both point-to-point and broadcast transmissions.

\section{Coverage}

Frequency: $150 \mathrm{MHz}$ to $1 \mathrm{z}$.

Mathematical Formulation

Hata Model for Suburban Areas is formulated as,

$$
L_{S U}=L_{U}-2\left(\log \frac{f}{28}\right)^{2}-5.4
$$

Where,

LSU = Path loss in suburban areas in decibel (dB).

$L U=$ Average Path loss in urban areas in decibel $(\mathrm{dB})$.

$\mathrm{f}=$ Frequency of Transmission in $\mathrm{MHz}$

COST-231 MODEL: The COST-Hata-Model is the most often cited of the COST 231 models. Also called the Hata Model PCS Extension, it is a radio propagation model that extends the Hata Model (which in turn is based on the Okumura Model) to cover a more elaborated range of frequencies. COST (Cooperation européenne dans le domaine de la recherché Scientifique et Technique) is a European Union Forum for cooperative scientific research which has developed this model accordingly to various experiments and researches.

Applicable To / Under Conditions: This model is applicable to urban areas. To further evaluate Path Loss in Suburban or Rural Quasi-open/Open Areas, this path loss has to be substituted into Urban to Rural/Urban to Suburban Conversions.

\section{Coverage}

Frequency: $1500 \mathrm{MHz}$ to $2000 \mathrm{MHz}$

Mobile Station Antenna Height: up to $10 \mathrm{~m}$

Base station Antenna Height: $30 \mathrm{~m}$ to $100 \mathrm{~m}$

Link Distance: up to $20 \mathrm{~km}$

Mathematical Formulation: The COST-Hata-Model model is formulated as,

$L=46.3+33.9 \log f-13.82 \log h_{B_{-}-} a\left(h_{R}\right)+[44.9-$

$\left.6.55 \log h_{B}\right] \log d+C$

$$
\begin{gathered}
\text { a }\left(\mathrm{h}_{\mathrm{R}}\right)=(1.1 \log \mathrm{f}-0.7) \mathrm{h}_{\mathrm{r}}-1.56 \log \mathrm{f}-0.8 \\
C=\left\{\begin{array}{l}
0 d B \text { for medium cities and suburban areas } \\
3 d B \text { for metropolitan areas }
\end{array}\right. \\
\text { Where } \\
\mathrm{L}=\text { Median path loss. Unit: Decibel }(\mathrm{dB}) \\
\mathrm{f}=\text { Frequency of Transmission. Unit: } \\
\text { Megahertz (MHz) } \\
\mathrm{h}_{\mathrm{B}}=\text { Base Station Antenna effective height. } \\
\text { Unit: Meter (m) } \\
\mathrm{d}=\text { Link distance. Unit: Kilometer }(\mathrm{km}) \\
\mathrm{h}_{\mathrm{R}}=\text { Mobile Station Antenna effective height. } \\
\text { Unit: Meter (m) } \\
\text { a ( }\left(\mathrm{h}_{\mathrm{R}}\right)=\text { Mobile station Antenna height } \\
\text { correction factor as described in the Hata Model } \\
\text { for Urban Areas. }
\end{gathered}
$$

\section{METHODOLOGY}

This study involves obtaining the mean receive power distribution at specified receiver distances from the respective Test GSM stations. In this study, measurements were taken at rural, suburban and urban areas within Lagos. Two sites each of rural, suburban and urban areas were used for this research. A site verification exercise was done using Ericsson K800i mobile station \& a piece of compass. This is to ensure that the BTS sites used were performing optimally and meets up with all parameters as stated:

BTS power: $40 \mathrm{~W}(45 \mathrm{dBm})$, MS Antenna ht: $1.5 \mathrm{~m}$, Connector loss: $3 \mathrm{~dB}$, Feeder loss: $2.58 \mathrm{~dB}$, Duplexer loss: $4.5 \mathrm{~dB}$,

MS Antenna gain: $14 \mathrm{dBi}$

BTS Antenna gain: $18.3 \mathrm{dBi}$, EIRP $P_{t}=67.22 \mathrm{dBm}$ Power conversion from Watt to $\mathrm{dBm}$ is done using the expression:

$$
P_{\mathrm{dBm}}=10 \mathrm{Log} \mathrm{P}_{\mathrm{mW}}
$$

Then, the effective power radiated from the BTS antenna $\left(P_{t \text { in } d B m}\right)$ is given as:

$$
\text { Where } \begin{array}{cc}
\mathbf{P}_{\mathrm{t}}=\mathbf{P}_{\mathrm{BTS}}-\mathbf{P}_{\text {con }}-\mathbf{P}_{\mathrm{D}}-\mathbf{P}_{\mathrm{f}}+\left(\mathbf{A}_{\mathrm{ms}}+\mathbf{A}_{\mathrm{BTS}}\right) \\
\mathrm{P}_{\mathrm{BTS}}= & \text { base station power } \\
\mathrm{P}_{\mathrm{D}}= & \text { duplexer loss } \\
\mathrm{P}_{\mathrm{f}}= & \text { feeder loss } \\
\mathrm{A}_{\mathrm{ms}}= & \text { Mobile station } \\
\text { (receiver) antenna gain } \\
A_{\mathrm{BTS}}= & \text { the base station } \\
\text { antenna gain } &
\end{array}
$$

The effective radiated power is subject to propagation loss $\left(P_{L}\right)$ along its path due to reflection, diffraction, retraction, scattering, etc. Power at the receiver distances from the base station is expressed as:

$$
\begin{aligned}
& P_{L}=P_{t}-P_{r} \quad \text { (in dBm) } \\
& P_{L}(d B)=10 \log _{10}\left(P_{t} / P_{r}\right)
\end{aligned}
$$


Different receive power levels (Rx_Level in $\mathrm{dBm}$ ) were obtained at different receiver distances from each sectors of the respective test stations (Adebayo and Edeko, 2006). The mean Rx_Level were then obtained. From the receive levels obtained, the Path loss values was then estimated. These values represent the field measurement values.

The obtained values from field measurements are then compared with those calculated using the existing models. The essence of this is to investigate the degree of consistency or variation between Pathloss values obtained for measurements and those values as postulated by the existing model i.e. field Okumura Hata Model.

\section{THE INVESTIGATED ENVIRONMENTS}

This investigation was carried out at different locations within Lagos State, South-West of Nigeria. Tests were carried out within two sites each of rural, suburban and urban areas. Rural areas selected are Imota and Ejinrin villages along Epe - Ikorodu road while two different sites were selected within suburban areas Epe town. Urban areas selected within are located within Lekki and Victoria Island axis of Lagos State.

\section{EXPERIMENTAL EQUIPMENT SETUP}

The experiment was performed using the set of equipments as connected below. These equipments were placed in a vehicle maintained at an average speed of $30 \mathrm{~km} / \mathrm{h}$.

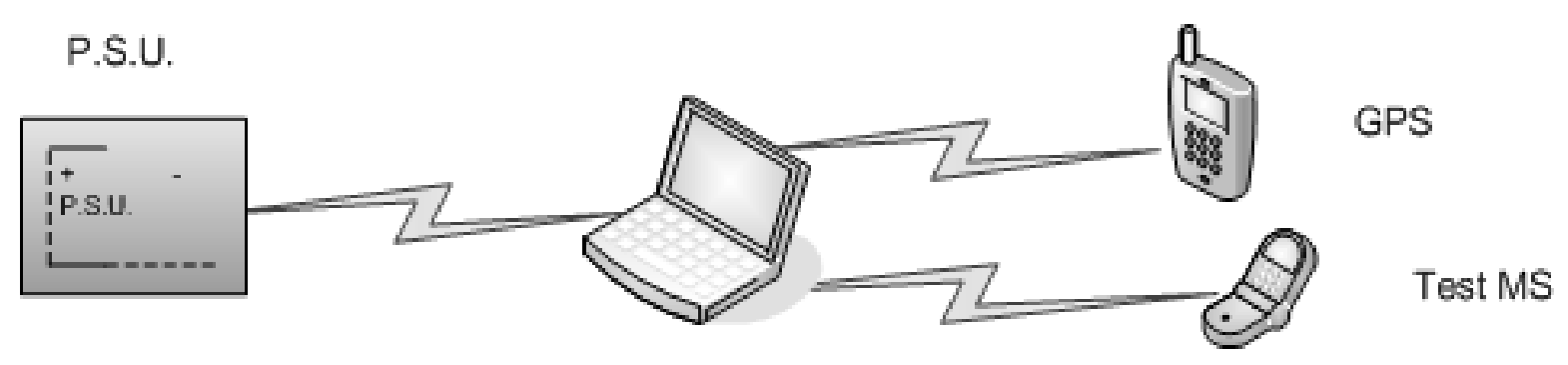

Personal Computer with

Data collection software

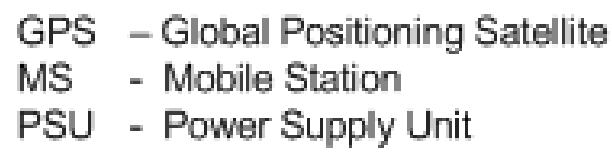

Fig 3.2: Experimental Equipment Setup

Power Supply Unit: The power supply unit provides the source of power for the entire system. It usually consists of an inverter which inverts the $12 \mathrm{~V}$ dc power from the vehicle to $220 \mathrm{~V}$ ac required by the data collection gadget.

Personal Computer: The personal computer houses the operating system and the data collection software (Ericsson TEMS Investigation 8.0). The personal computer serves as the communication hub for all other equipments in the system.

GPS: The Global Positioning System GPS operates with global positioning satellites to provide the location tracking for the system during data collection. It enables the system to determine its position on a global map which has been installed on the personal computer.

Test Mobile Station : The test mobile phone connects to the personal computer and it is used to initiate calls during the data collection. The behaviour of this mobile station gives the behaviour of any mobile station within the network.

DATA COLLECTION: Data collection was done starting from a distance of less than $100 \mathrm{~m}$ from the base station. The vehicle then moves along the direction of the main lobes of each directional antenna away from the site until it gets to the coverage border. This process was repeated for each sector of the site under which the experiment was performed. 
Am. J. Sci. Ind. Res., 2011, 2(3): 438-455

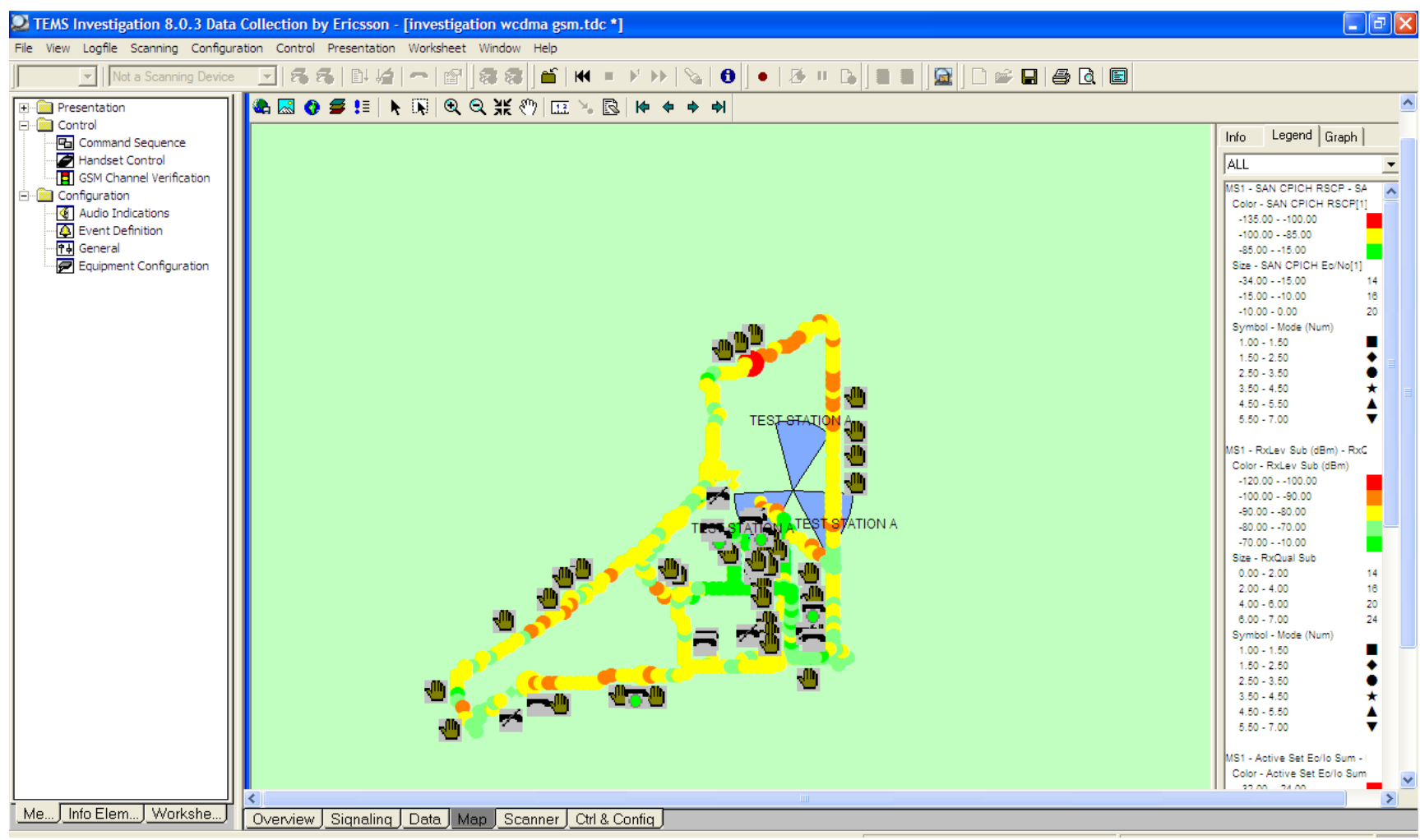

Fig 3.3: Drive Test Around Invetigated Area Using TEMS Investigation Software

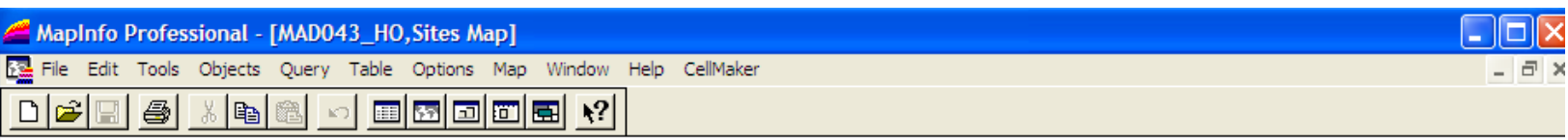

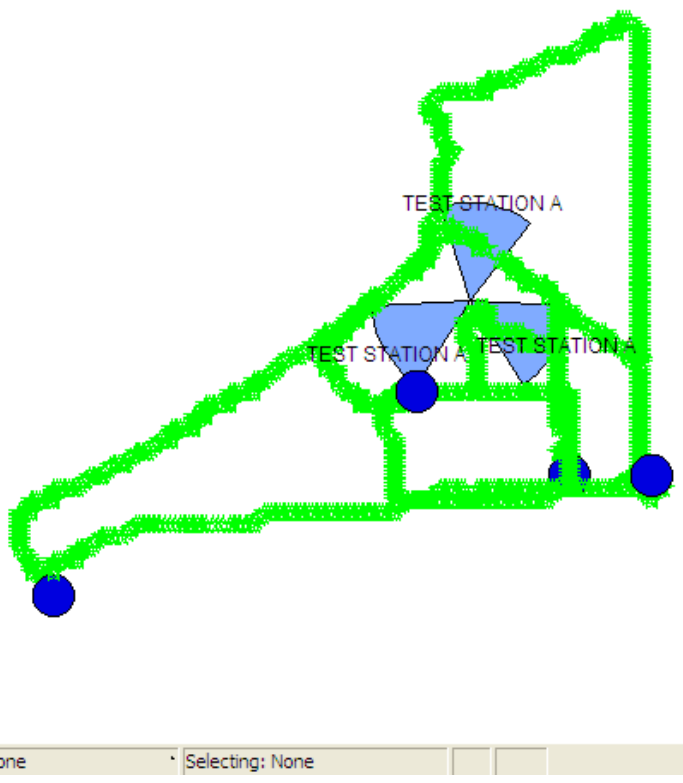

Fig 3.4: Map Info plot of one of the test sites.

443 
Am. J. Sci. Ind. Res., 2011, 2(3): 438-455

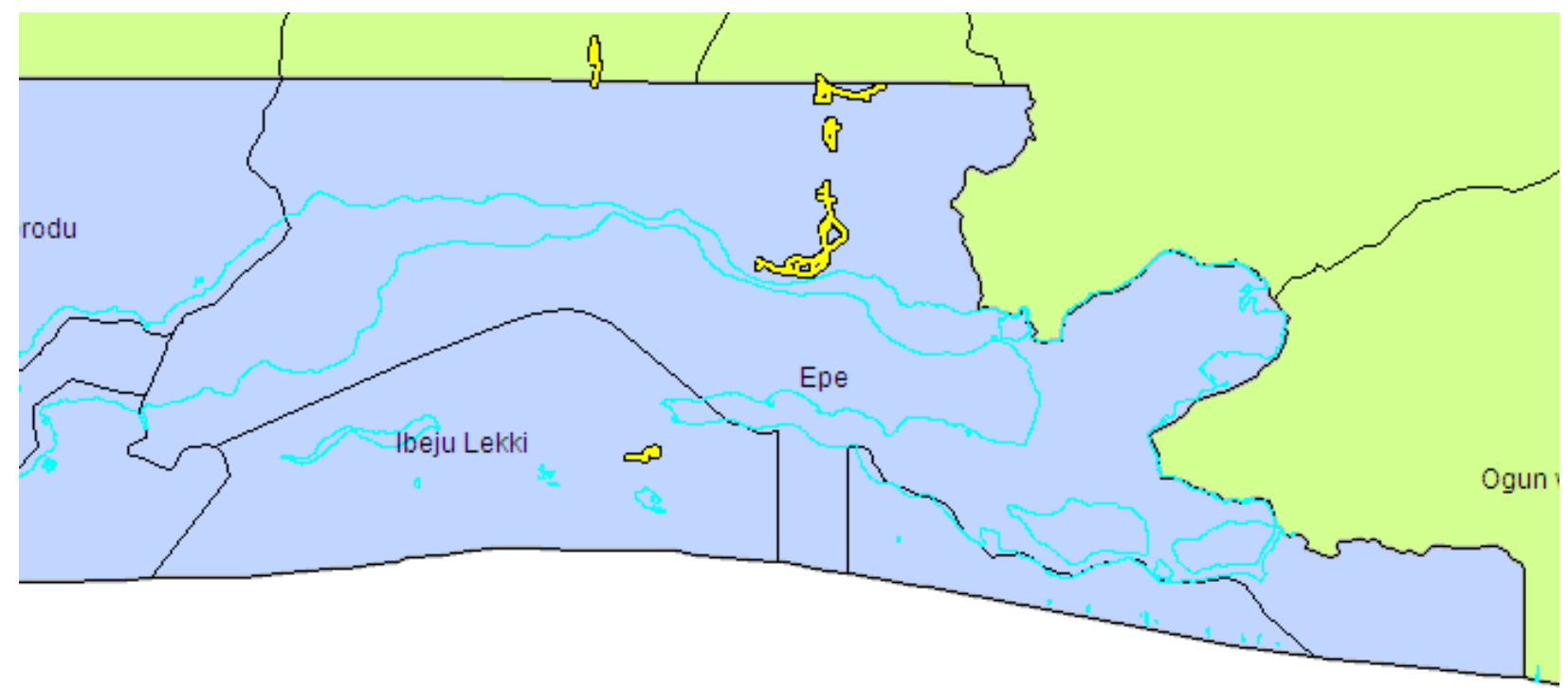

Fig 3.5: Map of Investigated Areas

Data obtained from field measurement: Two rural areas selected for this experiment are Imota and Ejinrin villages along Epe - Ikorodu road while two different sites were selected within suburban areas of Epe town. Urban areas selected are located within Lekki and Victoria Island axis of Lagos state. They are designated as Test Station A and Test Station B respectively. The table below shows the results obtained during the exercise. It presents the results obtained at each sector of the station at the respective receiver distances. 
This table below represents the data obtained from the rural area

Table 3.1: Receive Level for Rural Area

\begin{tabular}{|ccccccc|}
\hline & \multicolumn{3}{c}{ Receive Level $(\mathrm{dBm})$} & Distribution for RURAL AREA \\
TX/RX DISTANCE & \multicolumn{3}{c|}{ TEST STATION A } & \multicolumn{3}{c|}{ TEST STATION B } \\
0.5Km & SECTOR 1 & SECTOR 2 & SECTOR 3 & SECTOR 1 & SECTOR 2 & SECTOR 3 \\
$1.0 \mathrm{Km}$ & -40 & -48 & -44 & -48 & -44 & -46 \\
$1.5 \mathrm{Km}$ & -52 & -46 & -46 & -52 & -48 & -52 \\
$2.0 \mathrm{Km}$ & -56 & -54 & -58 & -52 & -52 & -52 \\
$2.5 \mathrm{Km}$ & -61 & -59 & -58 & -61 & -60 & -62 \\
$3.0 \mathrm{Km}$ & -64 & -66 & -65 & -63 & -60 & -66 \\
$4.0 \mathrm{Km}$ & -68 & -69 & -67 & -63 & -70 & -68 \\
$4.5 \mathrm{Km}$ & -72 & -76 & -82 & -69 & -92 & -71 \\
$5.0 \mathrm{Km}$ & -75 & -75 & -75 & -77 & -77 & -77 \\
$5.5 \mathrm{Km}$ & -78 & -73 & -75 & -78 & -78 & -78 \\
$6.0 \mathrm{Km}$ & -82 & -83 & -81 & -88 & -83 & -85 \\
$6.5 \mathrm{Km}$ & -89 & -90 & -88 & -85 & -85 & -85 \\
$7.0 \mathrm{Km}$ & -90 & -90 & -90 & -90 & -89 & -92 \\
$7.5 \mathrm{Km}$ & -96 & -94 & -95 & -91 & -91 & -91 \\
$8.0 \mathrm{Km}$ & -97 & -97 & -97 & -105 & -105 & -105 \\
$8.5 \mathrm{Km}$ & -98 & -98 & -98 & -102 & -96 & -98 \\
$9.0 \mathrm{Km}$ & -102 & -100 & -98 & -100 & -102 & -99 \\
$9.5 \mathrm{Km}$ & -106 & -108 & -104 & -102 & -102 & -102 \\
$10.0 \mathrm{Km}$ & -109 & -109 & -109 & -109 & -109 & -109 \\
& -110 & -110 & -110 & -122 & -118 & -120 \\
\hline
\end{tabular}


Am. J. Sci. Ind. Res., 2011, 2(3): 438-455

This table below represents the data obtained from the suburban area.

Table 3.2: Receive Level for Suburban Area

\begin{tabular}{|ccccccc|}
\hline & \multicolumn{5}{c}{ Receive Level $(\mathrm{dBm})$} & Distribution for SUBURBAN AREA \\
TX/RX DISTANCE & TEST STATION A & \multicolumn{3}{c|}{ TEST STATION B } \\
\hline 0.5Km & -58 & -60 & -57 & SECTOR 1 & SECTOR 2 & SECTOR 3 \\
$1.0 \mathrm{Km}$ & -63 & -64 & -64 & -54 & -56 & -52 \\
$1.5 \mathrm{Km}$ & -68 & -69 & -68 & -60 & -60 & -60 \\
$2.0 \mathrm{Km}$ & -75 & -75 & -75 & -70 & -69 & -72 \\
$2.5 \mathrm{Km}$ & -81 & -83 & -85 & -75 & -75 & -75 \\
$3.0 \mathrm{Km}$ & -86 & -86 & -86 & -80 & -82 & -79 \\
$4.0 \mathrm{Km}$ & -80 & -82 & -89 & -80 & -80 & -80 \\
$4.5 \mathrm{Km}$ & -84 & -84 & -84 & -88 & -90 & -87 \\
$5.0 \mathrm{Km}$ & -89 & -89 & -89 & -88 & -88 & -88 \\
$5.5 \mathrm{Km}$ & -92 & -90 & -91 & -89 & -89 & -89 \\
$6.0 \mathrm{Km}$ & -98 & -98 & -98 & -94 & -92 & -93 \\
$6.5 \mathrm{Km}$ & -98 & -98 & -98 & -94 & -94 & -94 \\
$7.0 \mathrm{Km}$ & -106 & -108 & -105 & -102 & -102 & -102 \\
$7.5 \mathrm{Km}$ & -113 & -116 & -114 & -104 & -104 & -104 \\
$8.0 \mathrm{Km}$ & -110 & -111 & -110 & -98 & -102 & -99 \\
$8.5 \mathrm{Km}$ & -120 & -120 & -120 & -108 & -108 & -108 \\
$9.0 \mathrm{Km}$ & -106 & -106 & -107 & -102 & -102 & -102 \\
$9.5 \mathrm{Km}$ & -108 & -108 & -108 & -120 & -120 & -120 \\
$10.0 \mathrm{Km}$ & -119 & -118 & -116 & 120 & -119 & -122 \\
& & & & -113 & -113 & -114 \\
\hline
\end{tabular}


Am. J. Sci. Ind. Res., 2011, 2(3): 438-455

This table below represents the data obtained from the urban area.

Table 3.3: Receive Level for Urban Area

\begin{tabular}{|ccccccc|}
\hline & \multicolumn{5}{c}{ Receive Level $(\mathrm{dBm})$} & Distribution for URBAN AREA \\
TX/RX DISTANCE & SECTOR 1 & SECTOR 2 & SECTOR 3 & SECTOR 1 & SECTOR 2 & SECTOR 3 \\
0.5Km & -57 & -58 & -56 & -58 & -58 & -59 \\
$1.0 \mathrm{Km}$ & -67 & -69 & -69 & -69 & -67 & -68 \\
$1.5 \mathrm{Km}$ & -72 & -72 & -72 & -74 & -76 & -73 \\
$2.0 \mathrm{Km}$ & -79 & -79 & -79 & -75 & -75 & -75 \\
$2.5 \mathrm{Km}$ & -80 & -82 & -79 & -79 & -78 & -78 \\
$3.0 \mathrm{Km}$ & -80 & -80 & -81 & -88 & -88 & -88 \\
$4.0 \mathrm{Km}$ & -90 & -90 & -90 & -86 & -87 & -87 \\
$4.5 \mathrm{Km}$ & -90 & -91 & -90 & -94 & -94 & -94 \\
$5.0 \mathrm{Km}$ & -96 & -96 & -96 & -96 & -96 & -96 \\
$5.5 \mathrm{Km}$ & -108 & -104 & -102 & -99 & -102 & -100 \\
$6.0 \mathrm{Km}$ & -101 & -101 & -101 & -105 & -106 & -108 \\
$6.5 \mathrm{Km}$ & -104 & -104 & -104 & -100 & -100 & -100 \\
$7.0 \mathrm{Km}$ & -112 & -112 & -112 & -100 & -100 & -100 \\
$7.5 \mathrm{Km}$ & 101 & -101 & -101 & -114 & -114 & -113 \\
$8.0 \mathrm{Km}$ & -106 & -106 & -106 & -110 & -112 & -109 \\
$8.5 \mathrm{Km}$ & -112 & -112 & -112 & -108 & -108 & -108 \\
$9.0 \mathrm{Km}$ & -108 & -108 & -108 & -114 & -114 & -114 \\
$9.5 \mathrm{Km}$ & -117 & -119 & -118 & -112 & -112 & -112 \\
$10.0 \mathrm{Km}$ & -118 & -118 & -119 & -118 & -114 & -116 \\
\hline
\end{tabular}

Data obtained is based on site engineering parameters which vary from one test station to the other. To improve accuracy of this experiment, the mean of the data from each sector was obtained. This is called the Mean RxLevel in $\mathrm{dBm}$. Common to all the test stations are Transmit power $P_{B T S}(d B m)$, the connector loss $P_{\text {con }}$, duplexer loss $P_{D}$, feeder loss $P_{f}$, mobile station antenna gain $A_{M S}$ and base station antenna gain $A_{B T S}$. The effective power radiated from the base station antenna called Effective Isotropic Radiated Power EIRP $P_{t}$ was then calculated using the expression:
$P_{t}=P_{B T S}-P_{\text {con }}-P_{D}-P_{f}+\left(A_{m s}+A_{B T S}\right)$

This gives $P_{t}=67.22 \mathrm{dBm}$

For rural areas, analysis is based on the following parameters: Base station antenna height $50 \mathrm{~m}$ and Frequency band of $900 \mathrm{MHz}$.Other parameters used are as stated above.

With respect to Table 3.1, the table below was obtained. 
Am. J. Sci. Ind. Res., 2011, 2(3): 438-455

Table 4.1: The Mean Receive Level for Rural Area

\begin{tabular}{|c|cc|c|} 
& & & Mean RXLevel(dBm) Rural \\
\hline TX/RX DISTANCE & TEST STATION A & TEST STATION B & -45 \\
$1.0 \mathrm{Km}$ & -44 & -46 & -49 \\
$1.5 \mathrm{Km}$ & -48 & -50 & -54 \\
$2.0 \mathrm{Km}$ & -56 & -52 & -60 \\
$2.5 \mathrm{Km}$ & -59 & -61 & -64 \\
$3.0 \mathrm{Km}$ & -65 & -63 & -68 \\
$4.0 \mathrm{Km}$ & -68 & -68 & -73 \\
$4.5 \mathrm{Km}$ & -75 & -71 & -76 \\
$5.0 \mathrm{Km}$ & -75 & -77 & -80 \\
$5.5 \mathrm{Km}$ & -82 & -78 & -83 \\
$6.0 \mathrm{Km}$ & -81 & -85 & -87 \\
$6.5 \mathrm{Km}$ & -89 & -85 & -90 \\
$7.0 \mathrm{Km}$ & -90 & -90 & -93 \\
$7.5 \mathrm{Km}$ & -95 & -91 & -96 \\
$8.0 \mathrm{Km}$ & -97 & -105 & -98 \\
$8.5 \mathrm{Km}$ & -98 & -98 & -100 \\
$9.0 \mathrm{Km}$ & -100 & -100 & 104 \\
$9.5 \mathrm{Km}$ & -106 & -102 & -109 \\
$10.0 \mathrm{Km}$ & -109 & -109 & -115 \\
& -110 & -120 &
\end{tabular}

The last column represents the mean value of the RxLevel from the two test stations.

For suburban areas, analysis is based on the following parameters: Base station antenna height $40 \mathrm{~m}$ and Frequency band of $1800 \mathrm{MHz}$.Other parameters used are as stated above.

\section{Table 4.2: The Mean Receive Level for Suburban Area}

The last column represents the mean value of the RxLevel from the two test stations.

For urban areas, analysis is based on the following parameters: Base station antenna height $30 \mathrm{~m}$ and
With respect to Table 3.2, the table below was obtained.
Frequency band of $1800 \mathrm{MHz}$.Other parameters used are as stated above. 
Am. J. Sci. Ind. Res., 2011, 2(3): 438-455

With respect to Table 3.3, the table below was obtained.

Table 4.3: The Mean Receive Level for Urban Area

\begin{tabular}{|c|cc|c|}
\hline & Mean Receive Level $(\mathbf{d B m})$ & for URBAN AREA & \\
TX/RX DISTANCE & TEST STATION A & TEST STATION B & Mean RxLevel(dBm) Urban \\
${ } }$ & -56 & -58 & -57 \\
$1.0 \mathrm{Km}$ & -68 & -68 & -68 \\
$1.5 \mathrm{Km}$ & -72 & -74 & -73 \\
$2.0 \mathrm{Km}$ & -79 & -75 & -77 \\
$2.5 \mathrm{Km}$ & -81 & -79 & -80 \\
$3.0 \mathrm{Km}$ & -80 & -88 & -84 \\
$4.0 \mathrm{Km}$ & -90 & -86 & -88 \\
$4.5 \mathrm{Km}$ & -90 & -94 & -92 \\
$5.0 \mathrm{Km}$ & -96 & -96 & -96 \\
$5.5 \mathrm{Km}$ & -104 & -100 & -102 \\
$6.0 \mathrm{Km}$ & -101 & -106 & -103 \\
$6.5 \mathrm{Km}$ & -104 & -100 & -104 \\
$7.0 \mathrm{Km}$ & -112 & -100 & -106 \\
$7.5 \mathrm{Km}$ & -101 & -113 & -107 \\
$8.0 \mathrm{Km}$ & -106 & -110 & -108 \\
$8.5 \mathrm{Km}$ & -112 & -108 & -110 \\
$9.0 \mathrm{Km}$ & -108 & -114 & -112 \\
$9.5 \mathrm{Km}$ & -118 & -112 & -115 \\
$10.0 \mathrm{Km}$ & -118 & -116 & -117 \\
& & &
\end{tabular}

The last column represents the mean value of the RxLevel from the two test stations. 
Am. J. Sci. Ind. Res., 2011, 2(3): 438-455

The table below represents the mean Rx Level distribution for rural, suburban and urban areas.

Table 4.4: The Mean Receive Level for Rural, Suburban and Urban Area

\begin{tabular}{|c|c|c|c|}
\hline TX/RX DISTANCE & Mean RxLevel(dBm) Rural & Mean RxLevel(dBm) Suburban & Mean RxLevel(dBm) Urban \\
\hline $0.5 \mathrm{Km}$ & -45 & -56 & -57 \\
\hline $1.0 \mathrm{Km}$ & -49 & -62 & -68 \\
\hline $1.5 \mathrm{Km}$ & -54 & -69 & -73 \\
\hline $2.0 \mathrm{Km}$ & -60 & -75 & -77 \\
\hline $2.5 \mathrm{Km}$ & -64 & -81 & -80 \\
\hline $3.0 \mathrm{Km}$ & -68 & -83 & -84 \\
\hline $4.0 \mathrm{Km}$ & -73 & -84 & -88 \\
\hline $4.5 \mathrm{Km}$ & -76 & -86 & -92 \\
\hline $5.0 \mathrm{Km}$ & -80 & -89 & -96 \\
\hline $5.5 \mathrm{Km}$ & -83 & -92 & -102 \\
\hline $6.0 \mathrm{Km}$ & -87 & -96 & -103 \\
\hline $6.5 \mathrm{Km}$ & -90 & -100 & -104 \\
\hline $7.0 \mathrm{Km}$ & -93 & -103 & -106 \\
\hline $7.5 \mathrm{Km}$ & -96 & -107 & -107 \\
\hline $8.0 \mathrm{Km}$ & -98 & -109 & -108 \\
\hline $8.5 \mathrm{Km}$ & -100 & -111 & -110 \\
\hline $9.0 \mathrm{Km}$ & 104 & -113 & -112 \\
\hline $9.5 \mathrm{Km}$ & -109 & -114 & -115 \\
\hline $10.0 \mathrm{Km}$ & -115 & -115 & -117 \\
\hline
\end{tabular}


Table 4.5: The Pathloss for Field Measurement

PATHLOSS FROM FIELD MEASUREMENT

\begin{tabular}{|c|c|c|c|}
\hline TX/RX DISTANCE & Path Loss $(\mathrm{dBm})$ Rural & Path Loss $(\mathrm{dBm})$ Suburban & Path Loss (dBm) Urban \\
\cline { 1 - 1 } $\mathbf{0 . 5 \mathrm { Km }}$ & 112.22 & 123.22 & 124.22 \\
$\mathbf{1 . 0 \mathrm { Km }}$ & 116.22 & 129.22 & 135.22 \\
$\mathbf{1 . 5 \mathrm { Km }}$ & 121.22 & 136.22 & 140.22 \\
$\mathbf{2 . 0 \mathrm { Km }}$ & 127.22 & 142.22 & 144.22 \\
$\mathbf{2 . 5 \mathrm { Km }}$ & 131.22 & 148.22 & 147.22 \\
$\mathbf{3 . 0 \mathrm { Km }}$ & 135.22 & 150.22 & 151.22 \\
$\mathbf{3 . 5 \mathrm { Km }}$ & 137.22 & 151.22 & 155.22 \\
$\mathbf{4 . 0 \mathrm { Km }}$ & 143.22 & 153.22 & 159.22 \\
$\mathbf{4 . 5 \mathrm { Km }}$ & 147.22 & 156.22 & 163.22 \\
$\mathbf{5 . 0 K m}$ & 150.22 & 159.22 & 169.22 \\
$\mathbf{5 . 5 \mathrm { Km }}$ & 154.22 & 163.22 & 170.22 \\
$\mathbf{6 . 0 \mathrm { Km }}$ & 157.22 & 167.22 & 171.22 \\
$\mathbf{6 . 5 \mathrm { Km }}$ & 160.22 & 170.22 & 173.22 \\
$\mathbf{7 . 0 \mathrm { Km }}$ & 163.22 & 174.22 & 174.22 \\
$\mathbf{7 . 5 \mathrm { Km }}$ & 165.22 & 176.22 & 175.22 \\
$\mathbf{8 . 0 \mathrm { Km }}$ & 167.22 & 179.22 & 177.22 \\
$\mathbf{8 . 5 \mathrm { Km }}$ & 171.22 & 181.22 & 179.22 \\
$\mathbf{9 . 0 K m}$ & 176.22 & 182.22 & 182.22 \\
$\mathbf{9 . 5 \mathrm { Km }}$ & 182.22 & 183.22 & 184.22 \\
$\mathbf{1 0 . 0 \mathrm { Km }}$ & 186.22 & 183.22 & 188.22 \\
\hline
\end{tabular}


Am. J. Sci. Ind. Res., 2011, 2(3): 438-455

Table 4.6: Comparison of Pathloss for Field Measurement and Existing (Okumura-Hata) Model

\begin{tabular}{|c|c|c|}
\hline \multicolumn{3}{|c|}{ URBAN AREA } \\
\hline TX/RX DISTANCE & Model Pathloss(dBm) & Measured Pathloss in (dBm) \\
\hline $0.5 \mathrm{Km}$ & 123.66 & 124.22 \\
\hline $1.0 \mathrm{Km}$ & 134.26 & 135.22 \\
\hline $1.5 \mathrm{Km}$ & 140.46 & 140.22 \\
\hline $2.0 \mathrm{Km}$ & 144.86 & 144.22 \\
\hline $2.5 \mathrm{Km}$ & 148.28 & 147.22 \\
\hline $3.0 \mathrm{Km}$ & 151.06 & 151.22 \\
\hline $3.5 \mathrm{Km}$ & 153.42 & 155.22 \\
\hline $4.0 \mathrm{Km}$ & 155.47 & 159.22 \\
\hline $4.5 \mathrm{Km}$ & 157.27 & 163.22 \\
\hline $5.0 \mathrm{Km}$ & 158.88 & 169.22 \\
\hline $5.5 \mathrm{Km}$ & 160.34 & 170.22 \\
\hline $6.0 \mathrm{Km}$ & 161.6 & 171.22 \\
\hline $6.5 \mathrm{Km}$ & 162.89 & 173.22 \\
\hline $7.0 \mathrm{Km}$ & 164.04 & 174.22 \\
\hline $7.5 \mathrm{Km}$ & 165.08 & 175.22 \\
\hline $8.0 \mathrm{Km}$ & 166.07 & 177.22 \\
\hline $8.5 \mathrm{Km}$ & 166.99 & 179.22 \\
\hline $9.0 \mathrm{Km}$ & 167.87 & 182.22 \\
\hline $9.5 \mathrm{Km}$ & 168.7 & 184.22 \\
\hline $10.0 \mathrm{Km}$ & 169.48 & 188.22 \\
\hline
\end{tabular}

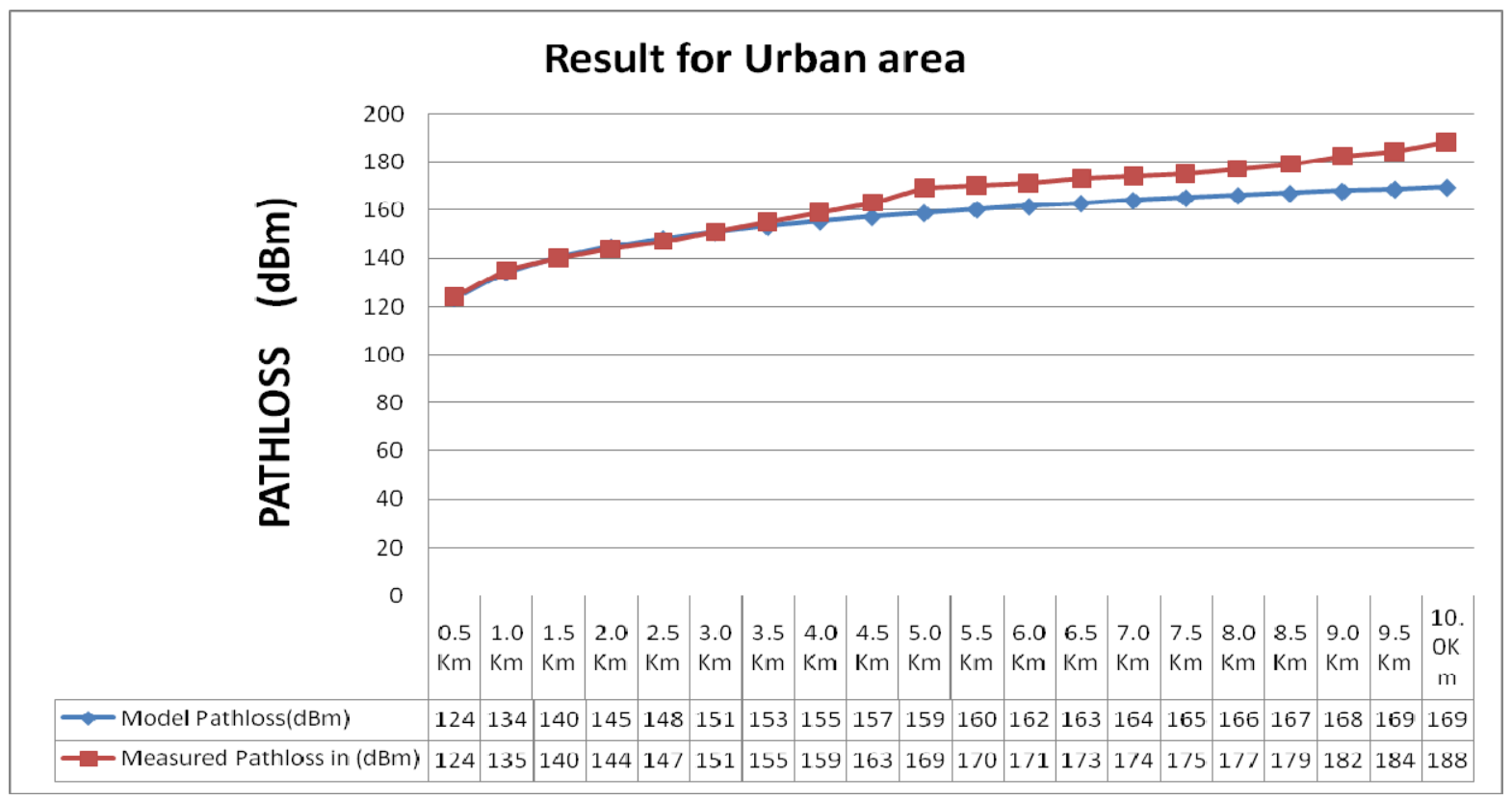


Am. J. Sci. Ind. Res., 2011, 2(3): 438-455

Table 4.7: Comparison of Pathloss for Field Measurement and Existing (Okumura-Hata) Model

\begin{tabular}{|c|c|c|}
\hline \multicolumn{3}{|c|}{ SUBURBAN AREA } \\
\hline TX/RX DISTANCE & Model Pathloss(dBm) & Measured Pathloss in (dBm) \\
\hline $0.5 \mathrm{Km}$ & 122.52 & 123.22 \\
\hline $1.0 \mathrm{Km}$ & 133.12 & 129.22 \\
\hline $1.5 \mathrm{Km}$ & 139.32 & 136.22 \\
\hline $2.0 \mathrm{Km}$ & 143.72 & 142.22 \\
\hline $2.5 \mathrm{Km}$ & 147.14 & 148.22 \\
\hline $3.0 \mathrm{Km}$ & 149.92 & 150.22 \\
\hline $3.5 \mathrm{Km}$ & 152.28 & 151.22 \\
\hline $4.0 \mathrm{Km}$ & 154.33 & 153.22 \\
\hline $4.5 \mathrm{Km}$ & 156.13 & 156.22 \\
\hline $5.0 \mathrm{Km}$ & 157.74 & 159.22 \\
\hline $5.5 \mathrm{Km}$ & 159.2 & 163.22 \\
\hline $6.0 \mathrm{Km}$ & 160.53 & 167.22 \\
\hline $6.5 \mathrm{Km}$ & 161.75 & 170.22 \\
\hline $7.0 \mathrm{Km}$ & 162.9 & 174.22 \\
\hline $7.5 \mathrm{Km}$ & 164.66 & 176.22 \\
\hline $8.0 \mathrm{Km}$ & 164.93 & 179.22 \\
\hline $8.5 \mathrm{Km}$ & 165.85 & 181.22 \\
\hline $9.0 \mathrm{Km}$ & 166.73 & 182.22 \\
\hline $9.5 \mathrm{Km}$ & 167.56 & 183.22 \\
\hline $10.0 \mathrm{Km}$ & 168.34 & 183.22 \\
\hline
\end{tabular}

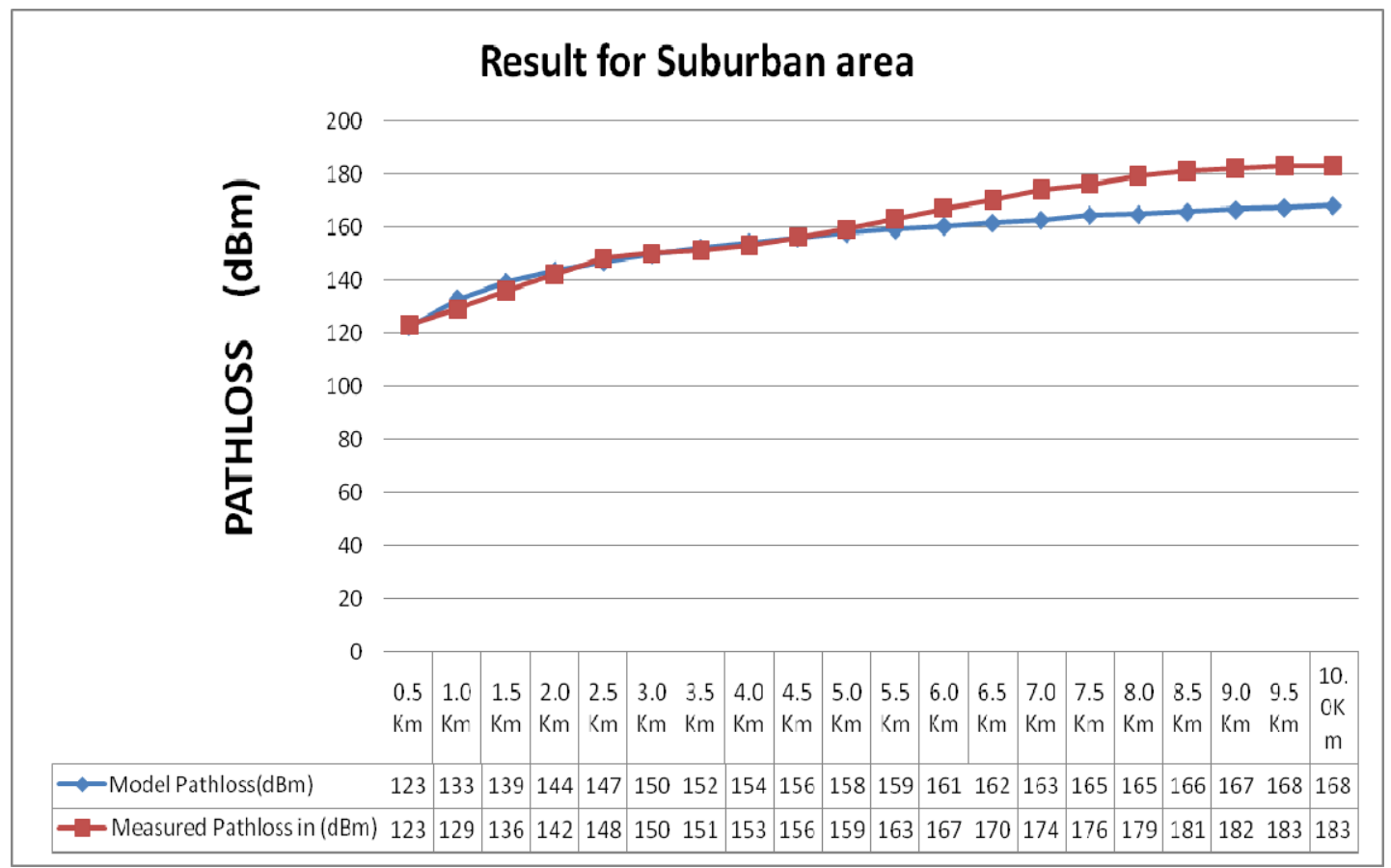


Am. J. Sci. Ind. Res., 2011, 2(3): 438-455

Table 4.8: Comparison of Pathloss for Field Measurement and Existing (Okumura-Hata) Model

\begin{tabular}{|c|c|c|}
\hline \multicolumn{3}{|c|}{ RURAL AREA } \\
\hline TX/RX DISTANCE(Km) & Model Pathloss(dBm) & Measured Pathloss in (dBm) \\
\hline $0.5 \mathrm{Km}$ & 84.63 & 112.22 \\
\hline $1.0 \mathrm{Km}$ & 94.8 & 116.22 \\
\hline $1.5 \mathrm{Km}$ & 100.75 & 121.22 \\
\hline $2.0 \mathrm{Km}$ & 104.97 & 127.22 \\
\hline $2.5 \mathrm{Km}$ & 108.24 & 131.22 \\
\hline $3.0 \mathrm{Km}$ & 110.91 & 135.22 \\
\hline $3.5 \mathrm{Km}$ & 113.18 & 137.22 \\
\hline $4.0 \mathrm{Km}$ & 115.13 & 143.22 \\
\hline $4.5 \mathrm{Km}$ & 116.86 & 147.22 \\
\hline $5.0 \mathrm{Km}$ & 118.41 & 150.22 \\
\hline $5.5 \mathrm{Km}$ & 119.8 & 154.22 \\
\hline $6.0 \mathrm{Km}$ & 121.08 & 157.22 \\
\hline $6.5 \mathrm{Km}$ & 122.25 & 160.22 \\
\hline $7.0 \mathrm{Km}$ & 123.34 & 163.22 \\
\hline $7.5 \mathrm{Km}$ & 124.35 & 165.22 \\
\hline $8.0 \mathrm{Km}$ & 125.3 & 167.22 \\
\hline $8.5 \mathrm{Km}$ & 126.19 & 171.22 \\
\hline $9.0 \mathrm{Km}$ & 127.03 & 176.22 \\
\hline $9.5 \mathrm{Km}$ & 127.82 & 182.22 \\
\hline $10.0 \mathrm{Km}$ & 128.57 & 186.22 \\
\hline
\end{tabular}

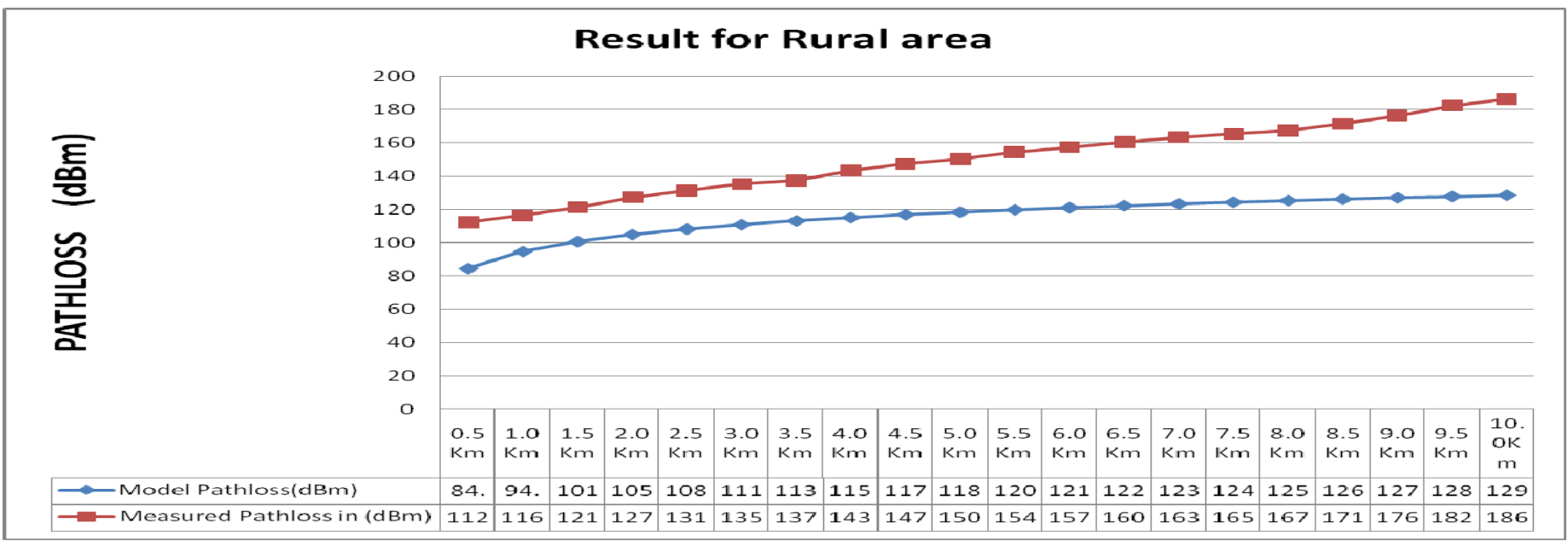


Am. J. Sci. Ind. Res., 2011, 2(3): 438-455

From the results of this research project, it is thereby recommended that: It is better to go for field measurement rather than relying on the existing empirical radio wave propagation models during equipment design and radio waves path profile estimation. Further planning of cellular network and equipment can rely on this model as typical for Nigerian terrain

\section{CONCLUSION}

The path loss distribution graph shows the relationship that exists among the various propagation models in terms of path loss. It can be seen that there are variations between field measurement results and the existing models. An exception is that of Okumura-Model for Rural areas in which only a large variation exists for the measured distances For rural areas, there is an appreciable deviation from the measured results. This research thus shows that the Okumura-Hata model for radio wave propagation is very effective for radio wave propagation pathloss prediction in sub-urban and urban areas in Western part of Nigeria.

\section{REFERENCES}

1. Arne Schmitz and Martin Wenig (2008) "The Effect of the Radio Wave Propagation Model in Mobile Ad Hoc Networks" Proceedings Of World Academy Of Science, Engineering And Technology Volume 36 December 2008 ISSN 2070-3740

2. T.L. Adebayo and F.O. Edeko (2006) "Characterisation of Propagation Path Loss at 1.8GHz:A Case study of Benin city, Nigeria." Research Journal of Applied Sciences: Medwell

3. Ajay Mishra (2007) "Advance Cellular Network Planning and Optimisation" John Wiley and Sons.

4. Shoewu, O and Adedipe, A (2010) "Investigation of Radio Wave Propagation Models in Nigerian Rural, and Surburban Areas" American Journal of Scientific and Industrial Research

5. Emagbetere, J.O. and Edeko, F.O. (2007) " An Evaluation of Outgoing Calls Quality of GSM Network Services in Oghara, Delta State" Research Journal od Applied Sciences Vol.2 No. 10 pg. 1016 - 1018

6. Emagbetere, J.O. and Edeko, F.O. (2007) “ Measurement Validation of Hata-Like Models for Radio Propagation Path Loss in Rural Environment at 1.8GHz Journal of Mobile Communication Vol. 3 No. 2 pg. $17-21$ 